\title{
Coracoclavicular and Costoclavicular Joints at a Common Juncture: A Rare Phenomenon
}

\author{
Articulaciones Coracoclavicular y Costoclavicular en una Unión Común: Un Raro Fenómeno
}

"Anita Rani; *'Suniti R. Mishra; "Jyoti Chopra; "Archana Rani; "Punita Manik; "Navneet Kumar \& "R. K. Dewan

RANI, A.; MISHRA, S. R.; CHOPRA, J.; RANI, A.; MANIK, P.; KUMAR, N. \& DEWAN, R. K. Coracoclavicular and costoclavicular joints at a common juncture: A rare phenomenon. Int. J. Morphol., 27(4):1089-1092, 2009.

SUMMARY: Movements at the human shoulder girdle are the result of complex interplay of glenohumeral, acromioclavicular, sternoclavicular and scapulothoracic articulations. Clavicle apart from articulating with the scapula and sternum is also connected with first rib by costoclavicular ligament and with coracoid process by coracoclavicular ligament. At times the area of attachment of these ligaments on clavicle, first rib and scapula show faceted apophysis suggesting the presence of additional diarthrodial articulations. Costoclavicular joint exists between clavicle and first rib and coracoclavicular joint between clavicle and coracoids process. Both these joints are described in the literature, but the concurrent occurrence of them in the same bone has not been reported yet. We found two clavicles, one of right and other of left side, both of them showed faceted apophysis for costoclavicular and coracoclavicular joint simultaneously, which is rare phenomenon.

KEY WORDS: Clavicle; Scapula; First rib; Costoclavicular ligament; Costoclavicular joint; Coracoclavicular ligament; Coracoclavicular joint.

\section{INTRODUCTION}

Human shoulder girdle comprises of glenohumeral, acromioclavicular, sternoclavicular and scapulothoracic articulations. Glenoid labrum, joint capsules and various supporting ligaments act as static stabilizers whereas muscles of rotator cuff, deltoid and scapular muscles serve as dynamic stabilizers of the shoulder girdle. Movements at the shoulder girdle are the result of the complex interplay of various static and dynamic stabilizers.

Sometimes the area of attachment of coracoclavicular ligament and costoclavicular ligament on the clavicle, and the respective areas on the scapula and first rib show evidence of diarthrodial articulations, resulting in two anomalous joints which further add to the complexity of already complex articulation.

Coracoclavicular joint, a synovial articulation between the clavicle and coracoid process of scapula, is a well studied entity and has an incidence of $0.8-9.8 \%$ in various populations (Kaur \& Jit, 1991; Nalla \& Asvat, 1995;
Cho \& Kang, 1998; Gumina et al., 2002; Nehme et al., 2004). On the other hand, the costoclavicular joint a diarthrodial articulation between the clavicle and first rib, is less studied demographically, but still few studies carried out, describes an incidence of 2- $10 \%$ (Cave, 1961; Redlund-Jhonell, 1986).

This article describes two human clavicles, of right and left sides, which showed faceted apophysis for both coracoclavicular and costoclavicular joints, simultaneously in the same clavicle, a phenomenon rare to occur.

\section{MATERIAL AND METHOD}

During the routine annual survey of the osteology lab of the department of Anatomy, CSMMU, Lucknow, Uttar Pradesh, we came across two clavicles (right $\&$ left) with unusual facets. The bones were carefully observed and photographs were taken by Sony DSC-W35 digital camera.

\footnotetext{
* Department of Anatomy, CSM Medical University, Lucknow, India.

** Department of Anatomy, S N Medical College Agra, India.
} 
Both clavicles were relatively longer and bulkier.

Case 1. The sternal end of the left clavicle showed a triangular, depressed and pitted articular facet. The medial half of medial $2 / 3$ of shaft was triangular and an elevated $1.7 \mathrm{~cm}$ long and $0.4 \mathrm{~cm}$ wide oval facet was seen on its inferior surface near the sternal end. The lateral half of medial 2/3 of shaft was compressed from upside down and exhibited well defined rough, pitted projection from its anterior as well as inferior aspect. A well formed subclavian groove was seen on the inferior surface. Medial end of groove was continuous with medial anomalous facet while its lateral end was continuous with lateral abnormal facet. A very small nutrient foramen was seen posterior to subclavian groove.

The lateral $1 / 3$ of shaft was wider anteroposteriorly with a well marked deltoid tubercle on its anterior border. The inferior surface was deeply concave. It exhibited an elevated well circumscribed circular facet of $1.2 \mathrm{~cm}$ diameter in place of conoid tubercle. Lateral to it an ill defined rough area corresponding to trapezoid ridge was present. No comments could be made about the acromial end of the bone, as it was mutilated (Fig. 1).
Case 2. The sternal end of right clavicle was triangular and had saddle shaped articular facet. The medial $1 / 3$ of the medial $2 / 3$ of the shaft was triangular and exhibited an elevated $1.8 \mathrm{~cm}$ long and $0.8 \mathrm{~cm}$ wide oval facet on its inferior aspect. Lateral $2 / 3$ of the medial $2 / 3$ of shaft was compressed from upside down and showed roughness and pitting on its anterior border as well as the adjacent part of inferior surface. A wide subclavian groove was present on the inferior surface. The posterior border of the subclavian groove was sharp and well defined towards its lateral end and was merging with the anomalous articular facet, present at the site of conoid tubercle.

The lateral $1 / 3$ of the shaft was flat with sharp anterior and posterior borders. Its anterior margin exhibited a well defined deltoid tubercle. The inferior surface was deeply concave and showed anelevated well circumscribed oval facet, $1.1 \mathrm{~cm}$ long and $0.7 \mathrm{~cm}$ in wide at the place of conoid tubercle. Lateral to it an ill defined rough area was present corresponding to trapezoid line. Lateral end presented a concave facet for articulation with acromian process (Fig. 2).

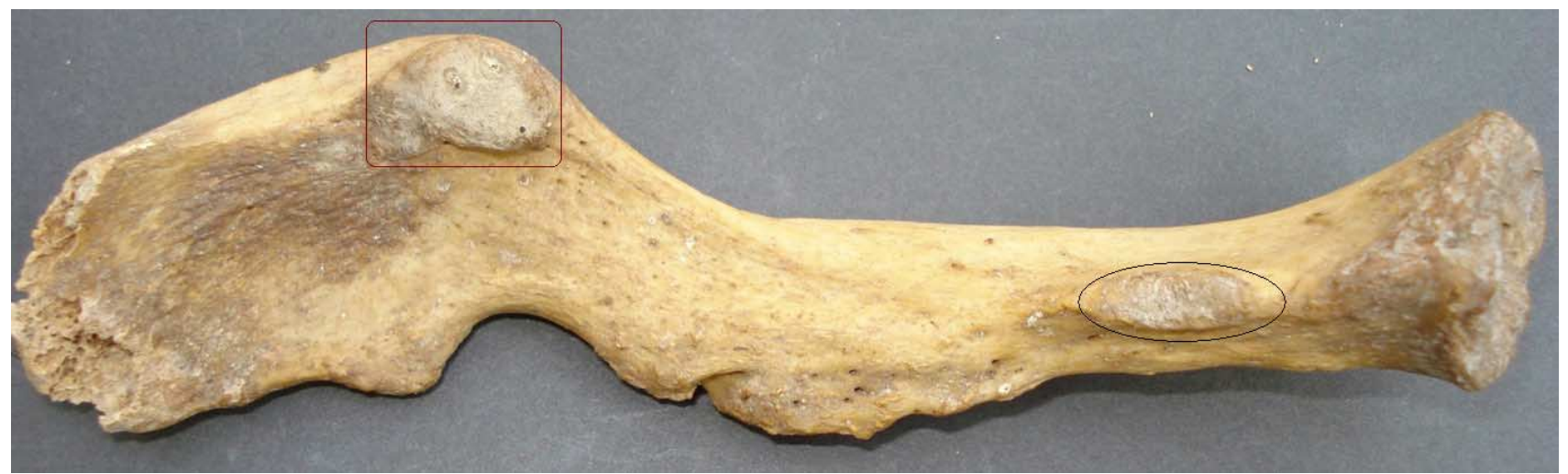

Fig. 1. Inferior surface of left clavicle showing faceted apophysis for costoclavicular joint (A) and coracoclavicular joint (B).

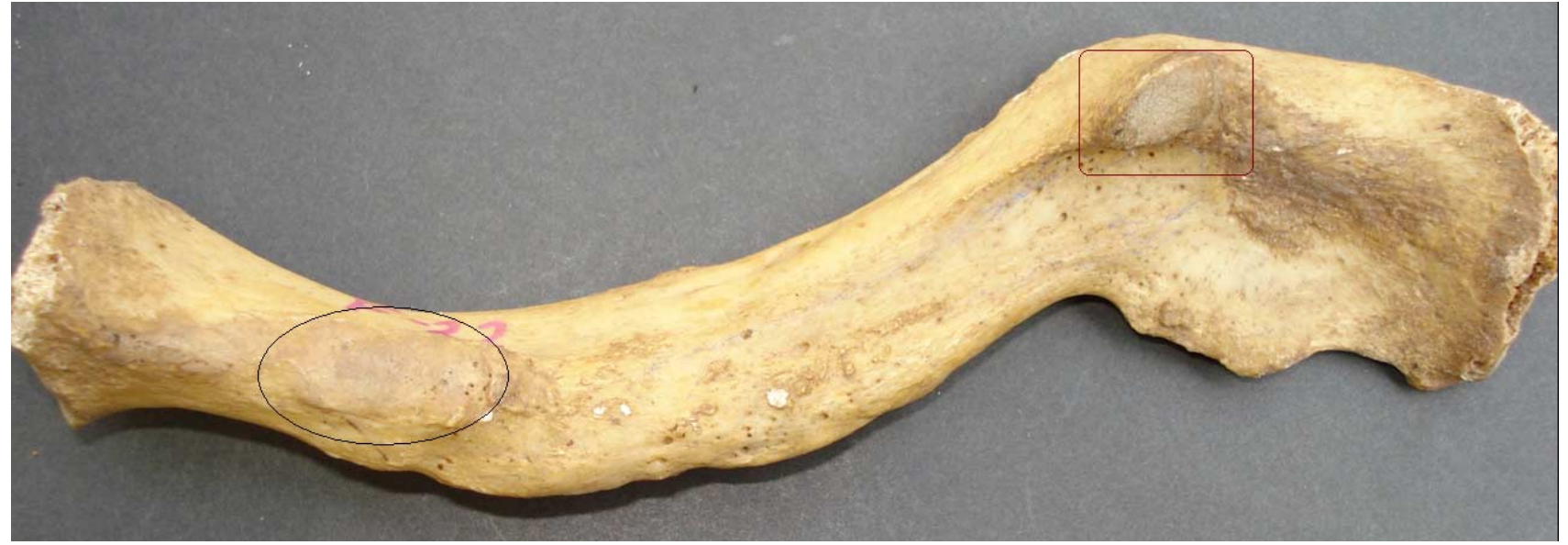

Fig. 2. Inferior surface of right clavicle showing faceted apophysis for costoclavicular joint (A) and coracoclavicular joint (B). 


\section{DISCUSSION}

Detailed study of both the clavicles strongly suggest that the additional faceted apophysis present towards the sternal and acromial ends of the inferior surface were due to the presence of anomalous costoclavicular and coracoclavicular joints respectively in the same individual.

Earliest description of costoclavicular articulation was given by Wood (1946), who proposed that in $10 \%$ subjects a joint exist between clavicle and first costal cartilage, and in such cases rhomboid ligament form part of the joint capsule. While studying the morphology of costoclavicular ligament, Cave reported that some times $(2.6 \%)$ costoclavicular attachment area on the clavicle has a smooth, elevated faceted apophysis which establishes diarthrodial articulation with a corresponding facet on the first rib. Redlund-Johnell provided radiological evidence of the costoclavicular joint in anteroposterior radiographs of lower cervical region of two patients, out of 950 patients, he observed.

Diarthrodial costoclavicular articulation is said to be a modification of ancestral syndesmosis. Costoclavicular ligament of Galogo and Loris was not a separate entity, but it was continuous with sternoclavicular joint capsule. In Gibbon, Orang and Chimpanzee the same ligament is recognized as a separate unit. Further, in Perodictius the costoclavicular ligament became bifascicular. In humans costoclavicular ligament is relatively larger in size, fibres are conical or cylindrical and has a distinct bursal cavity, suggesting an attempt towards diarthrodial articulation (Cave). It is proposed that the development of an emphatic type of costoclavicular ligament or a synovial type of costoclavicular joint is secondary to wide range of clavicular movements. So, probably it is a next step in the evolution.

Coracoclavicular joint is a true synovial joint which is represented by an articular facet on the conoid tubercle of the clavicle and the superior surface of the coracoid process of the scapula. Magnetic Resonance Imaging also confirms (Sener et al., 1996) that this is a true synovial joint with cartilage and synovial fluid. This anatomical variant has been described to be present in both human and non human primates (Haramati et al., 1994). As far as the description of the coracoclavicular joint in human is concerned, one of earliest report came from Poirier (1890), who found this joint in 3 out of 10 cadavers. 9.9\% incidence of coracoclavicular joint in Japanese was documented by Ray (1959). Based on a survey of published material and a prospective radiological survey carried out in Malasia, the geographical distribution of coracoclavicular joint was described. It was found that the anomaly was more frequent in Asia than in Europe and
Africa (Cockshott, 1979). An extensive study on paired clavicles obtained from 1000 adult human subjects was carried out by Kaur \& Jit in the North-West Indian population and they reported $9.7 \%$ incidence of this joint.

Nalla \& Asvat studied the skeletons of 60 White and 180 Black South African individuals and observed that the coracoclavicular joint was present in 10\% Whites and 9.4\% Blacks. This result was contrary to that of Cockshott. Recently Gumina et al. surveyed 1020 clavicles of Italian origin to determine the prevalence of the coracoclavicular joint and found the articular facet in 8 clavicles $(0.8 \%)$. Nehme et al., studied 2192 chest X rays and 392 pairs of clavicles and scapulae in the population of Toulouse city (France). The coracoclavicular joint was noted in $0.82 \%$ and in $1.78 \%$ of the individuals examined in the radiological and osteological series respectively.

Lewis (1959) stated a higher incidence of coracoclavicular joint in males (11:1) than in females while Kaur \& Jit and Nalla \& Asvat denied the male dominance as they found no statistically significant difference between the sexes.

According to Frasseto (cited by Kaur \& Jit) the abnormal fixation of clavicle in cases of fracture surgical neck humerus may result in development of coracoclavicular joint. Kaur \& Jit observed that the facet for the coracoclavicular joint was absent in the fetuses, neonates and young children, therefore, concluded that this variant is not a congenital anomaly. The presence of the joint was not related to the occupation of the individuals. They also proposed that the formation of joint later in life is caused more by genetic than by environmental factors. Nehme et al. also supported the genetic origin of this variant and suggested that its occurrence is probably influenced by environmental factors.

Nalla \& Asvat observed that individuals possessing coracoclavicular joint showed statistically significant larger scapulae and longer first ribs. They hypothesized that the aforementioned morphometry may restrict associated movements of the scapulae, resulting in the development of this joint. Cho \& Kang studied the incidence of coracoclavicular joint in Korean Population and observed that the joint was not found in individuals below 40 years of age. Therefore, they correlated the occurrence of joint with aging. But they did not find any relation between the size of the scapulae and the presence of this joint.

Like other synovial joints of the body, coracoclavicular joint is not an exception for developing ostoearthritic changes. When osteoarthritis of this joint 
occurs, it causes shoulder pain (Nehme et al.), which can be alleviated by resecting the anomalous joint. After an operative resection it never occurs again on the same side. Gumina et al. statistically justified the assumption that the coracoclavicular joint is a predisposing factor for the degenerative changes of neighboring joints.

We can conclude from the ongoing discussion that the two anomalous synovial joints are described individually till now. To the best of our knowledge, concurrent occurrence of both the joints in the same individual has not been reported yet. Costoclavicular joint, a next step in evolution series and coracoclavicular joint, a regressive joint, both present at a common juncture is not only an interesting phenomenon but also compels us to explore out the incidence of this concurrent occurrence in various populations, functional impact on pectoral girdle movements and its clinical implications.

RANI, A.; MISHRA, S. R.; CHOPRA, J.; RANI, A.; MANIK, P.; KUMAR, N. \& DEWAN, R. K. Articulaciones coracoclavicular y costoclavicular en una union común: un raro fenómeno. Int. J. Morphol., 27(4):1089-1092, 2009.

RESUMEN: Los movimientos de la cintura escapular humana son el resultado de la interacción compleja de las articulaciones glenohumeral, acromioclavicular, esternoclavicular y escapulotorácica. La clavícula, aparte de la articulación con la escápula y el esternón también está conectada con la primera costilla por el ligamento costoclavicular y con el proceso coracoides por el ligamento coracoclavicular. A veces la zona de unión de estos ligamentos de la clavícula, la primera costilla y la escápula muestran procesos facetarios que sugieren la presencia de nuevas articulaciones diartrodiales. La articulación costoclavicular existe entre la primera costilla y la clavícula y la articulación coracoclavicular entre la clavícula y proceso coracoides. Ambas articulaciones están descritas en la literatura, pero la aparición simultánea de ellas en el mismo hueso no se ha informado aún. Se encontraron dos clavículas, uno del lado derecho y otra del lado izquierdo, las dos presentaron procesos facetarios para las articulaciones costoclavicular y coracoclavicular simultáneamente, lo cual es un fenómeno raro.

PALABRAS CLAVE: Clavícula; Escápula; Primera costilla; Ligamento costoclavicular; Articulación costoclavicular; Ligamento coracoclavicular; Articulación coracoclavicular.

\section{REFERENCES}

Cave, A. J. E. The nature and morphology of the costoclavicular ligament. J. Anat., 95:170-9, 1961.

Cho, B. P. \& Kang, H. S. Articular facets of the coracoclavicular joint in Koreans. Acta Anat. (Basel), 163(1):56-62, 1998.

Cockshott, W. P. The coracoclavicular joint. Radiology, 131:313-6, 1979.

Gumina, S.; Salvatore, M.; De Santis, R.; Orsina, L. \& Postacchini, F. Coracoclavicular joint: osteologic study of 1020 human clavicles. J. Anat., 201(6):513-9, 2002.

Haramati, N.; Cook, R. A.; Raphael, B.; Mcnamara, T. S.; Staron, R. B. \& Feldman, F. Coracoclavicular joint: normal variant in humans. A radiographic demonstration in the human and non human primate. Skeletal Radiol., 23(2):117-9, 1994.

Kaur, H. \& Jit, I. Brief communication: Coracoclavicular joint in Northwest Indians. Am. J. Phys. Anthropol., 85(4):457-60, 1991.

Lewis, O. J. The Coracoclavicular Joint. J. Anat., 93:296-303, 1959.

Nalla, S. \& Asvat, R. Incidence of the coracoclavicular joint in South African populations. J. Anat., 186:645-9, 1995.

Nehme, A.; Tricoire, J. L.; Giordano, G.; Rouge, D.; Chiron, P. \& Puget, J. Coracoclavicular joints. Reflections upon incidence, pathophysiology and etiology of the different forms. Surg. Radiol. Anat., 26(1):33-8, 2004.
Poirier, P. La clavicule et ses articulations. Journal l'Anatomie (Paris), 26:81-103, 1890.

Ray, L. J. Bilateral coracoclavicular articulations in the Australian Aboriginal. J. Bone Joint Surg. Br., 41:180-4, 1959.

Redlund-Johnell, I. The costoclavicular joint. Skeletal Radiol., 15:256, 1986.

Sener, R. N.; Alper, H.; Sagtas, E.; Oyar, O. \& Ustum, E. E. Bilateral synovial coracoclavicular joints: MRI demonstration. Eur. Radiol., 6(2):196-8, 1996.

Wood, J. F. Buchanan's Manual of Anatomy. $7^{\text {th }}$ Ed. London, Bailliere Tindall and Cox, 1946.

Correspondence to:

Dr. Anita Rani

Associate Professor

Department of Anatomy,

CSM Medical University

Lucknow

Uttar Pradesh, INDIA

Mobile: 9839604340

Email: anita72rani@yahoo.co.in

Received: 22-04-2009

Accepted: 27-07-2009 